\title{
Inflammatory bronchial polyps associated with asthma: resolution with inhaled corticosteroid
}

\author{
A. Niimi, R. Amitani, T. Ikeda, Y. Kubo, E. Tanaka, F. Kuze
}

\begin{abstract}
Inflammatory bronchial polyps associated with asthma: resolution with inhaled corticosteroid. A. Niimi, R. Amitani, T. Ikeda, Y. Kubo, E. Tanaka, F. Kuze. @ERS Journals Ltd 1995

ABSTRACT: In a 50 year old man who complained of cough and sputum, a small endobronchial tumour was found in the left main bronchus and was biopsied via bronchoscopy. The histological diagnosis was inflammatory polyp with marked infiltration of eosinophils.

Six years later, the patient developed asthma. At the same time, another polyp was found in the posterior basal bronchus of the right lower lobe. The appearance of the first polyp was unchanged endoscopically and histologically. Inhalation of beclomethasone dipropionate, $200 \mu \mathrm{g}$ b.i.d., was started, and symptoms of asthma soon subsided. In addition, the two polyps regressed and eventually disappeared after one year of treatment.

Inhaled corticosteroids, being noninvasive and relatively safe, appear to be a possible therapeutic option in inflammatory bronchial polyps, especially in cases where the patient has asthma as an underlying condition, or the polyps are small and their management is not urgent.
\end{abstract}

Eur Respir J., 1995, 8, 1237-1239.
Dept of Infection and Inflammation, First Clinic of Medicine, Chest Disease Research Institute, Kyoto University, Kyoto, Japan.

Correspondence: A Niimi

Department of Infection and Inflammation First Clinic of Medicine

Chest Disease Research Institute

Kyoto University

53 Kawahara-cho

Shogoin

Sakyo-ku

Kyoto 606

Japan

Keywords: asthma

eosinophils

inflammatory bronchial polyp

inhaled corticosteroid

Received: October 251994

Accepted after revision March 281995
Inflammatory bronchial polyps (IBP) may follow various conditions, such as chronic bronchial infection [1], aspiration of foreign bodies [2, 3], and inhalation injury $[4,5]$. We experienced a rare case of IBP associated with asthma [6,7], which totally disappeared after one year of inhaled beclomethasone dipropionate. To our knowledge, this is only the second report of IBP successfully treated with inhaled corticosteroid alone [8].

\section{Case Report}

In June 1987, a 50 year old man presented with a history of several years of cough and sputum production. He had been afebrile and denied wheezing or dyspnoea. He had worked as a potter for the past 26 yrs and had been exposed to silicates for 5-6 h.day ${ }^{-1}$. He had never smoked cigarettes and had no previous history of asthma, sinusitis or nasal polyps. Physical examination and laboratory tests were normal; blood eosinophil count was 285 cells $\cdot \mathrm{mm}^{-3}, 5 \%$ of the total leucocytes.

Bronchoscopy was performed after both a chest radiography film and chest computed tomography (CT) were found to be normal. It revealed a white-coloured, smoothsurfaced, small polypoid lesion on the anterior wall of the left main bronchus, which was biopsied and examined histologically. The specimen was lined with columnar epithelium and consisted of a fibrous stroma with many capillary vessels and marked infiltration of inflammatory cells, mainly lymphocytes and eosinophils. The basement membrane was focally thickened. A diagnosis of IBP was made (fig. 1). No micro-organisms were found in materials obtained by brushing of the polyp.

Antitussives, mucolytics and theophylline were prescribed, and the patient started wearing a mask in the factory. However, his cough or sputum did not improve. At follow-up bronchoscopy, performed in November 1988 and August 1989, the polyp was unchanged. Sputum cytology performed in December 1988 showed more than $80 \%$ of the cells to be eosinophils.

The patient was lost from our follow-up until his cough and sputum exacerbated and wheezing appeared for the first time in February 1993. He was admitted to our hospital in May 1993. He was in good general condition, but complained of episodic cough, wheezing and dyspnoea. Physical examination, including chest auscultation was normal. Laboratory tests revealed a white blood cell count of $7.9 \times 10^{9} \cdot \mathrm{L}^{-1}$ with $41.4 \%$ neutrophils, $42.9 \%$ lymphocytes, $9.6 \%$ eosinophils, $1.3 \%$ basophils and $4.8 \%$ monocytes, and total immunoglobulin $\mathrm{E}(\mathrm{IgE})$ of $178 \mathrm{IU} \cdot \mathrm{mL}^{-1}$ (normal $<165 \mathrm{IU} \cdot \mathrm{mL}^{-1}$ ). Specific IgE antibodies against several common allergens were all negative. Sputum cytology again showed more than $80 \%$ of the cells to be eosinophils. Chest and sinus radiography films and chest CT were normal.

Results of pulmonary function tests, performed when the patient was asymptomatic, were forced vital capacity (FVC) $3.7 \mathrm{~L}$ (103\% of predicted), forced expiratory 
a)

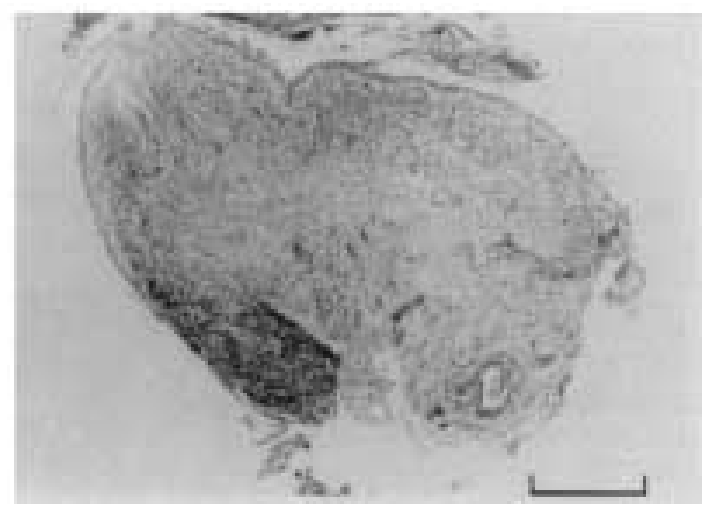

b)

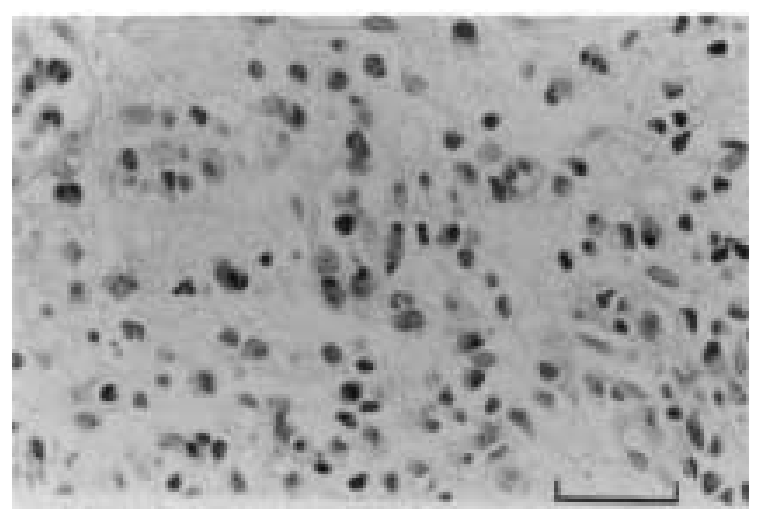

Fig. 1. - Photomicrograph of the biopsy specimen. Histological diagnosis of inflammatory bronchial polyp with marked infiltration of lymphocytes and eosinophils was made. Haematoxylin and eosin stain; a) magnification $\times 40$, scale bar $=500 \mu \mathrm{m}$; and b) magnification $\times 400$, scale bar=50 $\mu$ m.

a)

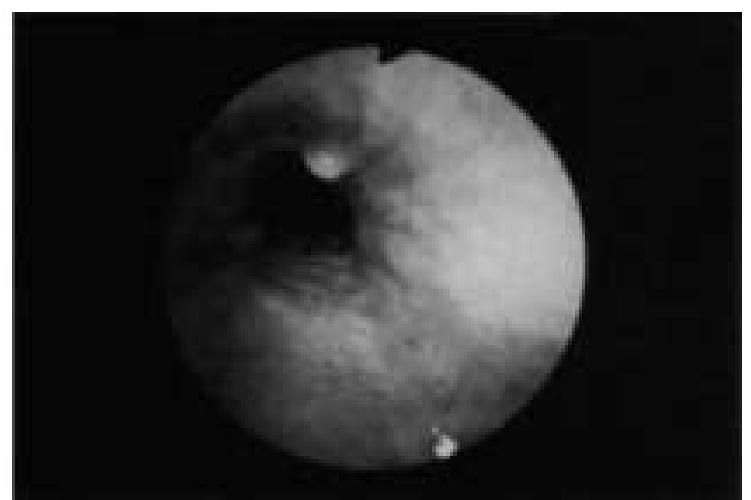

b)

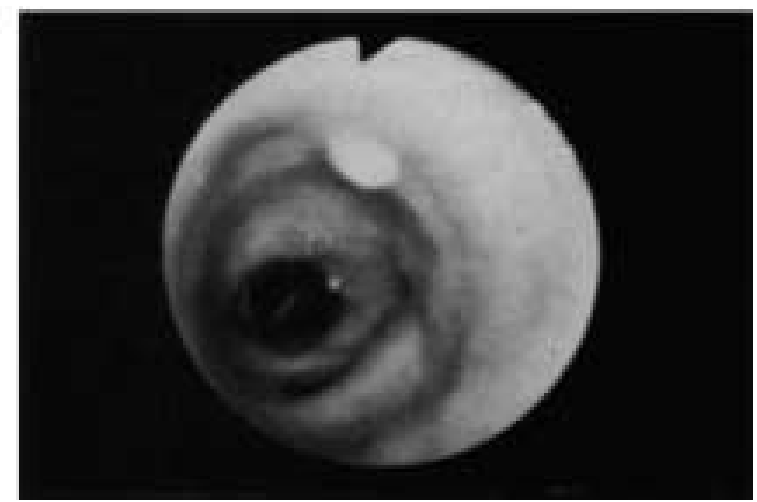

Fig. 2. - Bronchoscopic findings on admission, showing polyps in: a) the left main bronchus; and b) the anterior wall of the posterior basal bronchus of the right lower lobe.

a)

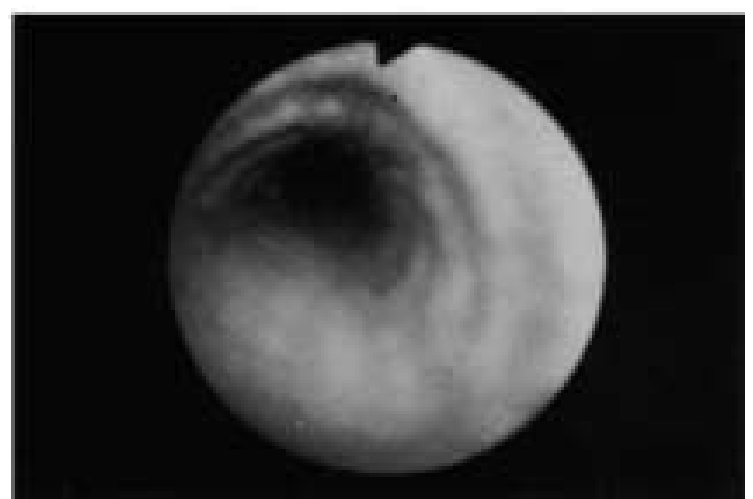

b)

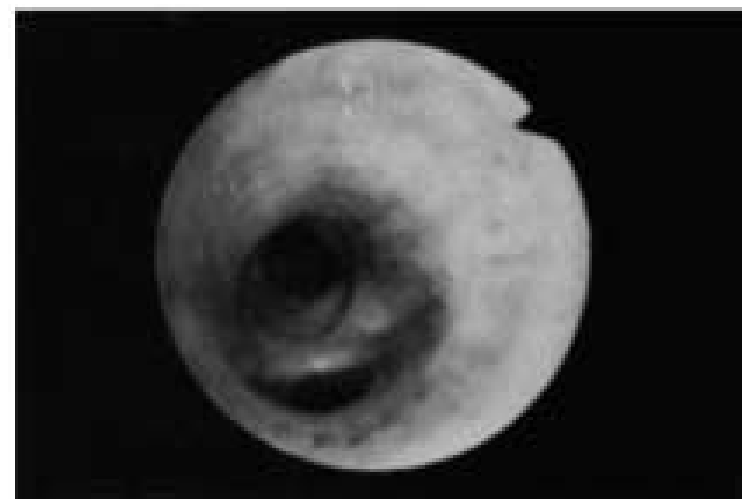

Fig. 3. - Bronchoscopic findings after one year of beclomethasone dipropionate: a) left main bronchus; and b) posterior basal bronchus of the right lower lobe. Both polyps have totally disappeared.

volume in one second (FEV1) 2.9 L (98\% pred) and FEV1/FVC 78\%. Methacholine inhalation challenge revealed marked bronchial hyperreactivity [9].

Inhaled $\beta_{2}$-agonist, procaterol, markedly improved the patient's cough, wheezing and dyspnoea which indicated asthma. Bronchoscopy revealed a new polypoid lesion on the anterior wall of the posterior basal bronchus of the right lower lobe. The polyp at the left main bronchus was unchanged from the previous examinations (fig. 2). A biopsy of the original polyp again led to the histological diagnosis of IBP with infiltration of eosinophils. In addition to procaterol, beclomethasone dipropionate, $200 \mu \mathrm{g}$ b.i.d. daily, was initiated and the patient soon became asymptomatic. He was discharged in June 1993, and the same dose of beclomethasone has been continued. The polyps had regressed at bronchoscopy performed in November 1993, and eventually disappeared totally in May 1994 (fig. 3).

\section{Discussion}

Association of IBP with asthma is very uncommon: only two cases are reported in the literature $[6,7]$. In these cases, asthma had already existed for 9 yrs [6] and 30 yrs [7] when IBPs, which contained eosinophils, were found. In our case, an IBP with marked eosinophil infiltration had existed for 6 yrs, and sputum eosinophilia 
had also been observed before wheezing appeared. Theophylline had no anti-tussive effect. It is possible that, although bronchial reactivity to methacholine was not tested until wheezing appeared, nonasthmatic eosinophilic bronchitis [10] had preceded the onset of asthma in this patient.

Coincidence of silicosis and IBP has been described previously [11]. The authors speculated that bronchitis secondary to silicosis might be the cause of IBP in their case. Although our patient had been occupationally exposed to silicates, chest radiography films or chest CT showed no findings suggestive of silicosis. The symptoms of asthma and the polyps regressed dramatically after an inhaled corticosteriod was initiated, whilst the patient continued working in the same environment. Moreover, the polyp showed infiltration of eosinophils in our case but not in the study by TASHIRO et al. [11]. Thus, no distinct correlation between exposure to silicates and the development of IBP was suggested in our case.

Several treatments have been reported for IBP, i.e. surgical resection, bronchoscopic excision, removal of foreign body, and medication with antibiotics. Effectiveness of systemic $[4,7]$ or systemic plus inhaled corticosteroids $[2,3,5]$ are also described. SMITH [8] found an IBP in a fireman chronically exposed to smoke. After 3 weeks of inhaled beclomethasone (dosage not stated), the polyp markedly regressed; the author regarded it as a response to the treatment [8]. In our case, the original polyp which was unchanged for 6 yrs as well as the newly developed polyp regressed and eventually disappeared with a small dosage of inhaled beclomethasone. We thus believe that the regression was not spontaneous but a response to the treatment. Inhaled corticosteroids are potent "antiinflammatory" agents, which are now used as first-line therapy for chronic asthma [12]. They can be administered easily with negligible systemic side-effects, unless the dose is very high [12]. Inhaled corticosteroids seem to be a possible therapeutic option in IBP, especially in cases of concomitant asthma, provide that the polyps are not obstructing the large airways and thus making their management more urgent.
Acknowledgements: The authors thank R. Wilson, Host Defence Unit, National Heart and Lung Institute, London, UK, for his helpful comments and suggestions.

\section{References}

1. Ashley DJB, Danino EA, Davies HD. Bronchial polyps. Thorax 1963; 18: 45-49.

2. Berman DE, Wright ES, Edstrom HW. Endobronchial inflammatory polyp associated with a foreign body: successful treatment with corticosteroids. Chest 1984; 86: 483-484.

3. Moisan TC. Retained endobronchial foreign body removal facilitated by steroid therapy of an obstructing, inflammatory polyp. Chest 1991; 100: 270.

4. Park T, DiBenedetto R, Morgan K, Colmers R, Sherman E. Diffuse endobronchial polyposis following a titanium tetrachloride inhalation injury. Am Rev Respir Dis 1984; 130: 315-317.

5. Adams C, Moisan T, Chandrasekhar AJ, Warpeha R. Endobronchial polyposis secondary to thermal inhalational injury. Chest 1979; 75: 643-645.

6. Argüelles M, Blanco I. Inflammatory bronchial polyps associated with asthma. Arch Intern Med 1983; 143: 570-571.

7. Shale DJ, Lane DJ, Fisher CWS, Dunnill MS. Endobronchial polyp in an asthmatic subject. Thorax 1983; 38: 75-76.

8. Smith RE. Endobronchial polyp and chronic smoke injury. Postgrad Med J 1989; 65: 785-787.

9. Takishima T, Hida W, Sasaki H, Suzuki S, Sasaki T. Direct-writing recorder of the dose-response curves of the airway to methacholine. Chest 1981; 80: 600606.

10. Gibson PG, Dolovich J, Denburg J, Ramsdale EH, Hargreave FE. Chronic cough: eosinophilic bronchitis without asthma. Lancet 1989; i: 1346-1348.

11. Tashiro T, Goto J, Yakushinzi M, et al. A case of nonspecific inflammatory polyp of the bronchus. JJSB 1987; 9: 48-52.

12. Barnes PJ, Pedersen S. Efficacy and safety of inhaled corticosteroids in asthma. Am Rev Respir Dis 1993; 148: S1-S26. 